\title{
A estética do bisonho: reflexões sobre a vocalidade no teatro de Philippe Quesne
}

Towards an aesthetics of the untrained (bisonho): reflections on the vocality of Philippe Quesne's theatre

Rafaella Uhiara ${ }^{1}$ Ana Wegner ${ }^{2}$ 


\section{Resumo}

Este estudo aborda o trabalho da companhia Vivarium Studio, dirigida por Philippe Quesne sob o prisma de sua estética vocal. Explorando qualidades vocais em territórios delicados como a ineloquência, o destreino, a desarticulação, a timidez, a insegurança e a inaudibilidade, o Vivarium Studio faz um elogio à "falta de jeito", que aqui chamamos de "bisonho". O interesse de tal característica é o fato de ela parecer não se enquadrar nem na "vocalidade" contemporânea, que enfatiza a materialidade sonora da voz, muitas vezes em detrimento do sentido, nem nas técnicas de voz que prezam a clareza da elocução. $O$ artigo busca, deste modo, refletir sobre tipo de vocalidade pouco contemplado pelos métodos de interpretação e teorias teatrais, procurando expandir a noção de vocalidade.

Palavras-chave: Vocalidade; teatro contemporâneo; Philippe Quesne; ineloquência; bisonho.

\section{Abstract}

This article examines the work of the Vivarium Studio Company, directed by Philippe Quesne, through the prism of vocal aesthetics. It focuses on vocal qualities typically considered as failed, and thus unwanted, including: non-eloquence, shyness, insecurity, inexperience and inaudibility. The Vivarium Studio is explored for how it enriches our reflection of bisonho, a Brazilian word signifying clumsiness. This concept takes into account uses of the stage that are not normally addressed by contemporary Voice Studies, ones that emphasize the sonic materiality of voice while sometimes disdaining meaning and interpretative methods that value clarity of enonciation. This article thus reflects on the particular kind of vocality that is ignored by dominant interpretation methods and theatrical theories, seeking to expand the notion of vocality.

Keywords: Vocality; contemporary theatre; Philippe Quesne; inarticulateness; clumsiness.
ISSN: 1414.5731

E-ISSN: 2358.6958
1 Bacharel em Direção Teatral pela ECA-USP e mestre em Estudos Teatrais pela Sorbonne Nouvelle, onde cursa o doutorado, com bolsa de Doutorado Pleno no Exterior da CAPES. Filiada ao laboratório de pesquisa THALIM do CNRS (França). rafa.uhiara@gmail.com
2 Atriz e pesquisadora, Doutoranda em Estudos Teatrais na Universidade Paris 8 em cotutela de tese com a Universidade de São Paulo. Bolsista do programa de Doutorado Pleno no Exterior da CAPES. ana wegner@yahoo.fr 
Bisonho $\mid$ adj.

1. Diz-se do soldado que, por ser inexperiente, é acanhado nos movimentos e não sabe obedecer ao mando.

2. [Figurado] Que revela timidez, insegurança $=$ acanhado, tímido $\neq$ desembaraçado

3. Que tem pouca experiência ou habilidade. = inábil, inexperiente, verde

4. Que é sombrio ou mal-humorado (ex.: rosto bisonho). = carrancudo

(Dicionário Priberam da Língua Portuguesa, 2008-2013)

\section{Introdução: dando voz a uma outra vocalidade cênica}

Nas últimas décadas, a noção de "vocalidade" torna-se uma ferramenta incontornável nas pesquisas que tangem a estética vocal nas línguas inglesa, francesa ou portuguesa. Na teoria das artes cênicas o termo é empregado, na maioria dos casos, para diferenciar-se do termo "voz". Este estaria carregado de uma redução à esfera semântica, ou seja, à função de "portadora de sentido", intimamente ligada ao texto dramático. Já a "vocalidade" pretende dar conta a dimensão corporal e material da voz. O presente artigo busca analisar o uso da voz no teatro da companhia Vivarium Studio, dirigida por Philippe Quesne, nome promissor da cena teatral europeia ${ }^{3}$, tentando identificar de que maneira a proposta vocal do diretor pode expandir a noção de vocalidade na paisagem teatral contemporânea.

\section{As noções de "Voz" e "Vocalidade"}

O teatro contemporâneo, em toda sua diversidade e apesar de suas incessantes transgressões, instaura suas próprias convenções estéticas. O "longo século XX" teatral, que se inicia no final do século XIX com a noção de "teatro de arte" e com a elevação da encenação como obra autoral, estabelece a forma como fim em si. Esse paradigma do reinado da forma se radicaliza no pós-guerra, sobretudo a partir das décadas de 1960 e 1970, tornando a experimentação como um valor fundamental da cena. O Elogio da forma reflete-se na emissão vocal do ator: há uma tendência de privilegiar a voz como meio, atendo-se à questão da sonoridade voz. Um indício flagrante desse fenômeno é a substituição do termo "voz" por "vocalidade"4 nos dicionários de teatro de Patrice Pavis. Em todas as edições de seu Dictionnaire du théâtre (1980, 1987, 1996 e 2002), encontramos somente o verbete "voz". Em seu novo dicionário, dedicado exclusivamente ao teatro contemporâneo e à performance (Pavis, 2014), esse termo dá lugar à "vocalidade":

A vocalidade é a voz considerada em sua dimensão material, física, pulsional,

\footnotetext{
3 Nos últimos dez anos, Quesne já passou pelas principais cenas europeias e mundiais: Festival d'Avignon, Hebbel am Ufer (Berlim), Performa (Nova lorque), Festival d'Automne (Paris), International Summer Festival (Hamburgo), KAAI Theater (Bruxelas), Centre Pompidou (Paris), Festival Internacional Cervantino (Guanajuato, México), SESC São Paulo, Seoul Performing Arts Festival, Festival Internacional de Buenos Aires. Quesne foi nomeado em 2013 à direção do Théâtre des Amandiers, em Nanterre, um dos importantes polos do teatro contemporâneo na região parisiense financiado pelo orçamentos público."

4 Os dicionários não especializados de língua francesa e inglesa não incorporam o verbete vocalidade, na maioria deles o termo aparece como um derivado de vocal ou ele nem sequer aparece. O termo, no teatro, tem certamente influência do medievista suíço Paul Zumthor, que forja essa noção questionando as relações entre 0 oral e a escrita reivindicando a autonomia do fato oral primeiramente nos estudos literários medievais e abrange a questão em seguida para outras áreas. Refletindo sobre a oralidade Zumthor tem um papel histórico fundamental e transdisciplinar no que diz respeito a valorização des "qualidades e valores (físicos, psíquicos e simbólicos) atrelados à voz humana como tal" (Zumthor, 2008, p.171)
} 
afetiva. No teatro, é o valor estético da voz. Portanto, não se trata da voz como portadora do sentido da linguagem articulada, mas da voz como matéria musical e física que os artistas podem utilizar para o canto, para a elocução, para a expressividade afetiva, em suma, para tudo o que pode servir à representação cênica (Pavis, 2014, p. 278).

Tal evolução terminológica é assim marcada por uma tentativa de unir voz e corpo e de não restringir a produção vocal à sua função semântica. Fator sem dúvidas enriquecedor para a estética vocal nas artes cênicas, de um modo geral. Porém esse deslocamento do sentido para o jogo com a materialidade propiciou em certas correntes do teatro contemporâneo europeu ${ }^{5}$ um franco desdém em relação ao sentido. Como ilustra o caso da companhia francesa Théâtre du Radeau:

A dicção se dá no fenômeno dos corpos. Ela é quase sempre inaudível, apesar das expectativas contrárias, porque ela se confronta com a convenção de que um ator em cena teria necessariamente algo a dizer. Esse teatro, que abre igualmente à possibilidade vazia de vir ao teatro contatar objetos dispostos "em série" sobre o palco, pela vã demonstração de uma performance é inútil. ${ }^{6}$

Para dar exemplo mais recente, o autor, encenador e diretor de teatro público, Pascal Rambert, faz uma declaração semelhante, opondo sua escrita para "potências vocais" a "personagens de papel ou de teatro", o termo "teatro" utilizado de modo pejorativo:

\begin{abstract}
Meu trabalho consiste em escrever para vozes e corpos ao invés de escrever para personagens. Eu escuto as vozes, eu as vejo. É concreto. Trata-se de seres humanos e não de personagens de papel ou de teatro. [...] Meu processo criativo funciona sempre pelo agrupamento de corpos no espaço, de corporeidades, de potências vocais. Eu escrevo para certas tessituras que funcionam em meu ouvido de maneira totalmente subjetiva. ${ }^{7}$
\end{abstract}

Por fim, o deslocamento no teatro contemporâneo do sentido para a materialidade, evidenciado pela gradual substituição do termo "voz" pelo termo "vocalidade", já havia sido observado e descrito por Hans-Thies Lehmann em O teatro pós-dramático (2007), sobretudo "Corporalidade", em que o autor propõe que "o corpo torna-se centro de gravidade, não como portador de sentido, mas em sua substância física e seu potencial gestual", ou "corporalidade autossuficiente". Em suma, a teoria da estética teatral contemporânea parece sobrestimar "o valor estético da voz", desmerecendo muitas vezes o sentido.

Philippe Quesne leva à cena um tipo de emissão vocal pouco contemplados pelos métodos de interpretação canônicos nem pela vocalidade contemporânea. Ele nos chama a atenção por explorar qualidades vocais em territórios delicados como

\footnotetext{
5 Por contemporâneo, entende-se um gênero do teatro atual, com suas próprias regras e convenções, e não as diversas manifestações possíveis do teatro atualmente.

6 "La diction se tient dans le phénomène des corps. Elle est, contre toute attente, inaudible le plus souvent, parce qu'elle se confronte à une attitude déjà convenue qui est celle qu'un acteur se présente sur scène, et qu'il aurait nécessairement quelque chose à dire. Ce théâtre, qui ouvre également à cette possibilité vide de venir constater des objets placés en série sur le plateau, pour la démonstration vaine d'une performance, est inutile". François Tanguy, entrevistado por Véronique Hotte, « Rencontre avec... ». In: Du théâtre, n. 22, Actes Sud, 1998, p. 13.

7 "Mon travail consiste à écrire pour des voix et des corps plutôt que pour des personnages. [...] Je les entends, je les vois. C'est concret. Ce sont des êtres humains, pas des personnages de papier ou de théâtre. [...] J'ai toujours fonctionné par assemblage de corps dans l'espace, de corporalités, de puissance de voix". Pascal Rambert, " Avoir les bons mots et les mettre ensemble - Entretien avec Pascal Rambert, propos recueillis par Joëlle Gayot », folder do espetáculo Répétition, T2G - Théâtre de Gennevilliers, centre dramatique national, Festival d'Automne à Paris, 2014.
} 
a ineloquência, o destreino, a desarticulação e a inaudibilidade. Essas características não parecem interessar nem a tradição em torno do texto, já que elas dificultam a compreensão, nem à "vocalidade" contemporânea, já que elas orbitam o sentido e a linguagem articulada, negligenciando propositalmente a exploração sonora da voz.

Apesar de integrar o circuito profissional de teatro contemporâneo francês e europeu, Vivarium Studio conserva propositalmente essas características estranhas dentro do que se esperaria de uma dita técnica de atuação. No teatro contemporâneo, a questão da presença continua sendo a pedra angular para além de toda estética. Uma vez que o ator se viu desvinculado da noção de personagem, livre para recorrer a um ecletismo estilístico e autorizado inclusive a negligenciar a técnica vocal, ele permaneceu compelido a continuar a responder ao cânone da presença. Esta pode se traduzir por uma a impressão de que o ator tem domínio do que está fazendo/dizendo e é completamente seguro de si.

Como veremos ao longo desse artigo, a interpretação do Vivarium faz um elogio à "falta de jeito", ao que chamamos de "bisonho", que, como podemos ver em epígrafe, caracteriza a timidez, a falta de experiência e a insegurança. Essa bisonhice torna a vocalidade do teatro de Quesne peculiar, pois a ancoragem corporal da voz não é impulso para a sua expansão, ao contrário: temos a impressão de que o corpo é o involucro do qual a voz não deve escapar demasiado. Um paralelo entre vocalidade e corporalidade se instaura. $O$ ator não sabe onde colocar as mãos: no bolso; cruzadas a trás das costas; coladas contra as coxas? Igualmente, o ator não sabe o que fazer com sua voz: o que dizer? Como dizer? O trabalho de Quesne nos parece jogar com dispositivos que demandam outras funções cênicas para a voz. Ela é usada como elemento de uma convenção interferindo diretamente na relação de cumplicidade entre o ator e o público.

\section{O Vivarium Studio}

O melhor modo de apresentar a companhia francesa é analisar seu nome: Vivarium Studio. Ela propõe um dispositivo teatral que se assemelha a um viveiro. Seu encenador, Philippe Quesne se interessa pela criação de dispositivos cênicos que coloquem o espectador em uma posição voyeurística de observador de um micromundo, como uma espécie de entomologista:

$\mathrm{Eu}$ acho que a particularidade [do Vivarium Studio] e também uma característica dos espetáculos é que eles são pequenos mundos para observar e o público é como um tipo de entomologista, que pode observar esses indivíduos, como pequenos insetos em mundos, que, aliás, os excedem (Quesne, 2010b).

Esse interesse pela perspectiva do espectador-entomologista levou Philippe Quesne, criador da companhia a tornar-se encenador. Formado em artes plásticas, a entrada de Quesne no teatro seu deu pela cenografia. Essa experiência fez com que ele assistisse cotidianamente a muitos ensaios. Essa rotina criou nele a sensação de

8 Je pense que la particularité [do Vivarium Studio], c'est aussi une caractéristique des spectacles, c'est que ce sont souvent des petits mondes à observer et le public est un peu comme une sorte d'entomologiste, pouvant observer ces petits individus, comme des petits insectes dans des mondes, qui, d'ailleurs, parfois, les dépassent. (Tradução nossa) 
observar, de modo distanciado, o ato de criação teatral, suscitando nele o desejo de reunir um grupo de amigos artistas plásticos, músicos e atores em um apartamento para experimentar melhor a questão do espectador-observador. Desses experimentos, advém o primeiro espetáculo da companhia, La démangeaison des ailes (2003) (Imagem I).

O grupo se mantém desde então, conservando o mesmo espírito. Referimo-nos não só a inclinação à pesquisa prática, mas também a utilização de recursos improvisados e reciclados a cada espetáculo e a um certo desprendimento em relação à "seriedade" do teatro. Os atores do Vivarium

De fato, nós somos nós mesmos em cena. Nunca tem nenhuma indicação psicológica. Então, a gente nem precisa se preocupar muito, o que simplifica as coisas, em todo caso, para mim, que não sou atriz de formação. Então, a gente não precisa ficar quebrando a cabeça para saber "eu encarno isso?", "eu tenho que estar triste?" alegre?". É isso, a gente só segue instruções muito muito concretas e precisas. (Angotti, 2010b) .

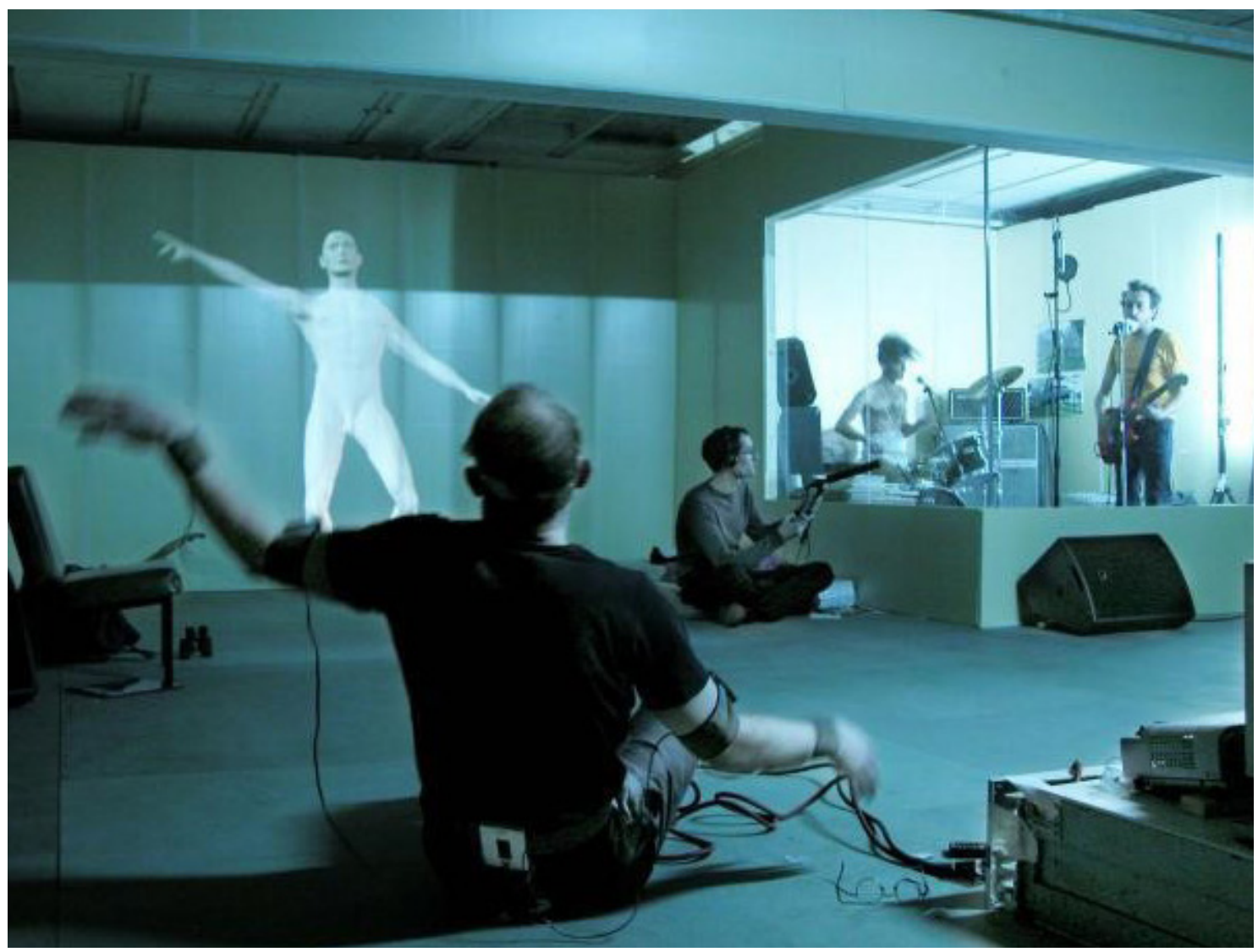

Imagem I - La démangeaison des ailes (2003). Vivarium Studio

Interpretação do Vivarium Studio pode ser melhor explicada pela participação, no elenco, de Hermès, o cachorro de um dos atores. Hermès não era treinado ${ }^{10}$. $O$ seu não-adestramento e sua impossibilidade de compreensão das convenções tea-

\footnotetext{
9 Effectivement, on est nous-mêmes sur scène. II n'y a jamais aucune indication psychologique. Donc on n'a jamais à se poser des questions, ce qui simplifie aussi les choses, en tout cas, pour moi, qui suis pas comédienne de formation. Et donc, on n'a pas à se poser des questions, savoir "est-ce que j'incarne ci ?", "est-ce que je dois être triste ? gaie ?". Voilà, on a juste des consignes très concrètes et très précises. (Tradução nossa)

10 Hermès faleceu em 2014. A companhia fez um minuto de silêncio em sua homenagem antes da reprise de La démangeaison des ailes na Ménagerie de Verre, em Paris: http://inferno-magazine.com/2014/06/11/philippe-quesne-la-demangeaison-des-ailes/ (Consultado em 30 de março de 2016).
} 
trais mostram exatamente o modo como o grupo aborda a presença dos atores em cena: o não-virtuosismo, a impressão de não domínio da cena, o risco iminente de falhas e acidentes, o teatro não levado "a sério". De fato, as falhas são muito bem-vindas: "A gente adora tudo o que dá errado!" - admite o encenador (Quesne, 2008a) ${ }^{11}$.

Podemos fazer um paralelo entre o tipo de interpretação "destreinada" dos atores de Quesne e o estudo feito por Sílvia Fernandes e Mauro Meiches sobre o ator brasileiro Carlos Moreno na companhia Pod Minoga ${ }^{12}$. Segundo os autores, o desempenho peculiar da interpretação de Moreno é oriundo do fato de ele vir do teatro amador e, assumindo-se como tal, não passarem por uma "formação a uma técnica tradicional":

Partindo de uma aceitação - não sei fazer o que se espera que um ator saiba - descobre uma maneira original de representar, usando sua inabilidade como ponto de partida. Já que não sabe falar direito, não sabe movimentar-se em cena e não quer esconder essas características, faz dela o ponto de partida para a criação de um estilo particular, que tem como marca exatamente essa falta de jeito. (Fernandes e Meiches 1988, p.152)

Os autores descrevem nessa análise o modo como o ator subverte a interpretação teatral com seu jeito amador de atuar, "identificado na falta de projeção de voz, em problemas de dicção, na ausência de um domínio corporal ou em dificuldades de movimentação" (idem, p. 153). Fernandes e Meiches ainda outros "defeitos" sublimados como a falta de segurança para representar, a inabilidade e falta de jeito. Reconhecemos as características observadas por Meiches e Fernandes no trabalho do Vivarium studio. Porém, no caso da companhia francesa, a falta de segurança para representar não provém somente do desejo de afirmação do amadorismo, mas da construção de estruturas que desestabilizam e fragilizam os atores.

Isso fica evidente no espetáculo Caspar Western Friedrich (2016), dirigido por Quesne com outros atores, da Kammerspiele de Munique. Estes, diferentemente dos atores do Vivarium Studio, não conseguem abafar o som de suas vozes bem treinadas. Um deles, Peter Brombacher, nos seus mais de trinta anos de carreira nas principais cenas alemãs, desde os primeiros sons pronunciados, não esconde os reflexos de apoios vocais bem enraizados, de uma grande complexidade de harmônicos vocais e de uma projeção sonora límpida. Philippe Quesne consegue, ainda assim, encontrar subterfúgios para honrar a estética do bisonho, como na cena em que o ator canta um lied de Schumann para o qual ele visivelmente não foi "treinado", acompanhado pelo som do piano, vindo de um toca-fitas portátil. O mesmo efeito é reproduzido quando, no mesmo espetáculo, Julia Riedler, claramente noviça na arte de tocar violão, "Mysteries", de Beth Gibbons, à luz de uma fogueira. Desafinada, fora de ritmo, debatendo-se com seu violão, a performance da atriz é de uma sinceridade comovente, que tange as fronteiras do cômico e do poético. Quesne leva assim frase de João Gilberto ao seu paroxismo "no peito de um desafinado também bate um coração".

Em um artigo sobre a recorrência do canto "frágil" e "bruto" (no sentido de mal

11 On adore tout ce qui rate. (Tradução nossa)

12 Grupo caracterizado pela criação coletiva, atuante na cena paulista entre 1972 et 1980. 
acabado) na cena contemporânea, Muriel Plana aborda a recorrência do canto "desengonçado" na cena contemporânea francesa. A autora analisa o fenômeno a partir das peças de André Angels e Jean-Louis Hourdin, onde "a voz dos intérpretes [...] se projeta com dificuldade, numa imperfeição involuntária e numa recusa da toda virtuosidade, técnica musical ou vocal" (Plana, 2012, p. 205) ${ }^{13}$. Há igualmente uma semelhança entre os termos empregados na análise de Muriel Plana e aqueles que usamos para descrever a vocalidade no teatro de Quesne. No entanto, uma diferença essencial separa a vocalidade frágil e bruta pela qual se interessa Muriel Plana e a bisonhice quesniana: nas peças que ela descreve, essa fragilidade é requerida somente na voz cantada enquanto que a voz falada executada registro. Essa falta de jeito da palavra cantada serviria para provocar no público uma emoção particular de "surpresa, inconforto, consternação e incômodo. Mesmo trabalhando o canto "frágil" e "bruto", Quesne não visa esse efeito de "quebra" posto que a voz falada também passa pelo mesmo destreino.

Mas se Quesne consegue subverter as vozes bem preparadas dos atores da Kammerspiele de Munique o mesmo não acontece com o corporeidade dos atores cuja toda e qualquer caminhada um preparo físico particularmente condicionado para estar em cena. Essa disparidade entre emissão vocal cantada e presença física dos atores corrobora ainda mais a construção da estética do bisonho no espetáculo Caspar Western Friedrich.

\section{Dos canevas incômodos que contribuem para a construção da bi- sonhice}

A presença sem jeito, bisonha, é, como vimos, construída. Um dos meios de construção de risco e fragilidade é o fato de os espetáculos de Philippe Quesne não passarem pela etapa escrita. A dramaturgia é estabelecida em processo e os diálogos nem sempre são realmente fixados. Todos os improvisos são precisamente organizados por balizas definidas em sala de ensaio como deslocamentos, situações, objetos. Segundo ele, o que estrutura o espetáculo é o trabalho com a música:

A música instaura climas. Em L'effet de Serge, comer uma pizza ouvindo piano cria um estado diferente da mesma cena, onde o ator comeria sua pizza ao som de uma sinfonia ou de Michael Jackson. [...] Na verdade, a música pode incarnar estados psicológicos sem que o ator precise se encarregar disso. (Aka, 2011, p. 9) (4 $^{14}$

Esse trabalho com a música não se limita à sala de ensaio: assim como um maestro, Philippe Quesne rege os tempos do espetáculo durante a apresentação. Não como um Tadeusz Kantor ${ }^{15}$; mais discreto, o cenógrafo não sobe ao palco. Ele se contenta em enviar indicações sonoras imperceptíveis para o público, da técnica,

\footnotetext{
13 [...] la voix des interprètes [...] s'élevait avec difficulté, avec une volontaire imperfection dans un refus de toute virtuosité et de toute technicité musicale ou vocale. (Tradução nossa).

14 La musique instaure des climats. Dans L'effet de Serge, manger une pizza en écoutant du piano crée un état différent de la même scène où le comédien mangerait sa pizza sur une symphonie ou sur du Michael Jackson. [...] En fait, la musique peut incarner des états psychologiques sans que l'acteur ne s'en charge. (Tradução nossa).

15 Tadeusz Kantor (1915-1990), artista plástico e um dos principais encenadores do século XX, conhecido por dar indicações aos seus atores em cena durante o espetáculo.
} 
que ele faz questão de operar em todos os seus espetáculos (Quesne, 2010b).

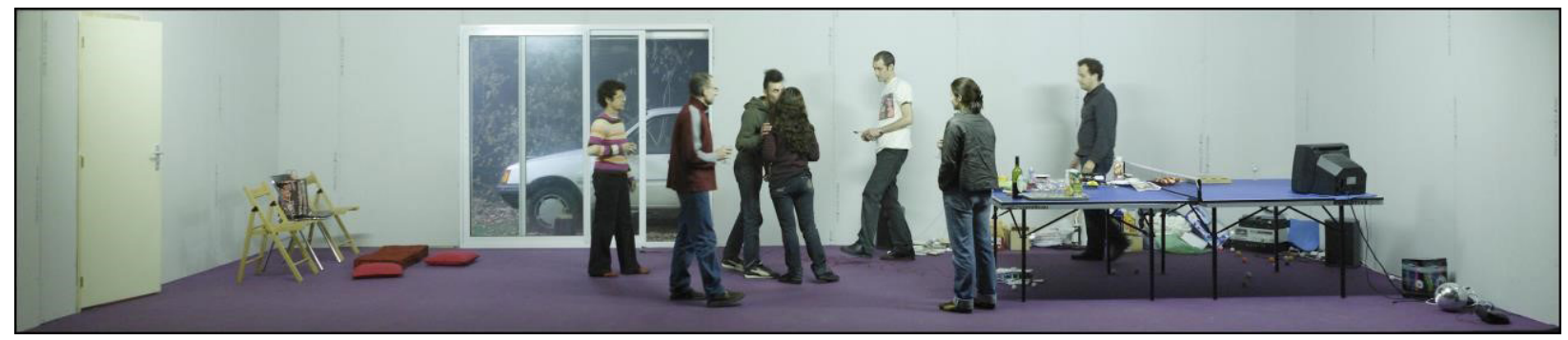

Imagem II - L'effet de Serge (2007). Foto: Martin Argyroglo

Tomemos o exemplo de L'effet de Serge (2007) (Imagem II). Gaëtan Vourc'h, que interpreta o protagonista, Serge, é o único a conhecer o espetáculo integralmente. Os atores que interpretam seus amigos - que visitam Serge todos os domingos para assistir a seus espetáculos caseiros de efeitos - são recrutados localmente e mudam a cada apresentação. Os atores convidados só descobrem o espetáculo na apresentação. Antes disso, eles recebem apenas algumas indicações: o momento de entrar em cena; aceitar alguma das bebidas propostas por Serge (água, suco de laranja ou vinho); reagir espontaneamente às apresentações dos espetáculos amadores de Serge e só deixar a cena ao ouvir um latido de cachorro ao fundo, enviado por Quesne. O controle da deixa para a saída dos convidados permite ao encenador de fazer com que eles fiquem em cena o suficiente para que o diálogo acabe e um silêncio constrangedor se instaure. Esses silêncios costumam gerar muitos risos na plateia. Essas situações de incômodo de não ter o que dizer e de puxar pequenos assuntos para tentar amenizar o desconforto são fundamentais para a emissão vocal e para a dramaturgia do espetáculo. Elas ajudam a construir uma espécie de solidão, que o tom ao mesmo tempo risível e melancólico, principal marca do Vivarium Studio.

\section{Aparatos tecnológicos que aumentam "o sentimento de incom- preensão"}

\section{A projeção da palavra escrita}

A bisonhice não está só na presença e no modo de falar, mas também no conteúdo e na forma dos diálogos. Alguns espetáculos que trabalham com a palavra escrita nos textos projetados - que, em alguns casos reiteram os diálogos ${ }^{16}$ - "denunciam" a ineloquência das falas. Um exemplo interessante é o primeiro espetáculo da companhia a utilizar esse recurso, D’après nature (2006), um espetáculo sobre o fim do mundo após uma catástrofe ambiental. Nele, as falas são sussurradas e inaudíveis da plateia. Elas são projetadas por escrito tais quais, permitindo que o público possa acompanhar o que está sendo dito. Assim, no exemplo ilustrado pela Imagem III, ve-

16 As legendas foram utilizadas pelo Vivarium Studio pela primeira vez em D'après nature (2006) como solução para que as falas sussurradas pelos atores fossem compreendidas pelo público. Ele reaparece em seguida em Échantillons (2006), descrevendo as pequenas cenas disparadas pelos espectadores por meio de um mouse, criando um duplo textual da ação cênica. Os textos projetados aparecem ainda em Anamorphosis (2012), como tradução das falas das atrizes japonesas; em La mélancolie des dragons (2008), na simulação de testes para o chamariz do parque de atrações dos personagens, e em Swamp Club (2013), em painéis. 
mos a seguinte fala: "Ça cuit combien de temps un céléri ?" ("quanto tempo pra cozinhar um aipo?"). Ela nos parece um excelente exemplo não só do tom leve e prosaico dos diálogos quesnianos - contrastante com a seriedade do tema do espetáculo -, mas também por sua construção sintática. O sujeito, "un céléri" (um aipo), aparece no fim da frase, mas se vê duplicado no início da frase pelo pronome "ça". Essa construção, extremamente informal, embora seja muito comum na linguagem oral, não deixa de causar um certo estranhamento, já que essa não é uma forma muito utilizada na linguagem escrita.

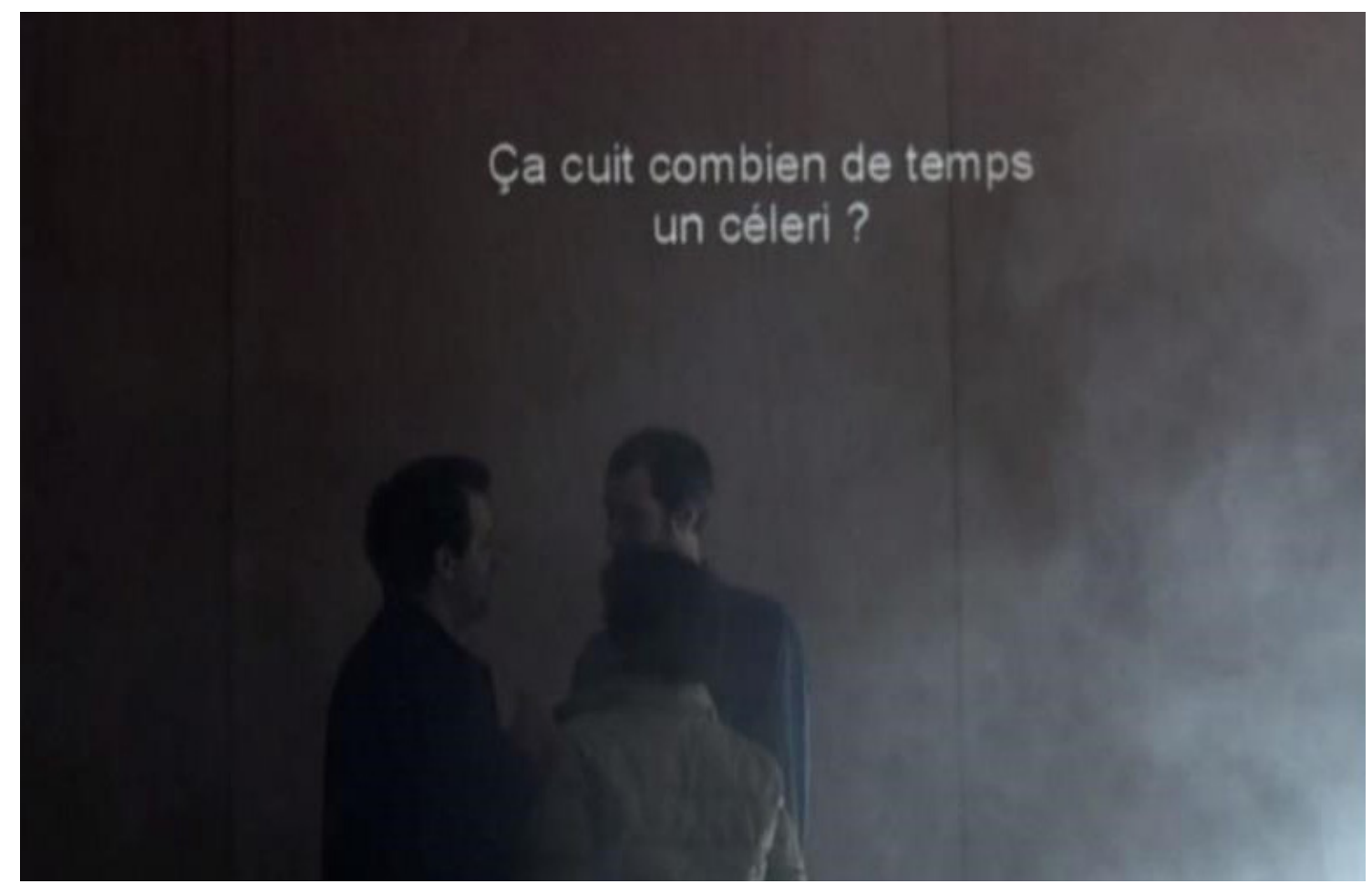

Imagem III - D’après nature (2006). Vivarium Studio

Um outro exemplo de jogo com as palavras escritas é explorado em Swamp Club (2013), onde o suporte da palavra são painéis luminosos do tipo led-scroller, que difundem constantemente mensagens textuais sem relação direta com os diálogos (Imagem IV). O fato de fazer desfilar as palavras, determina o tempo de leitura das frases, criando ainda outro tipo de relação com a imagem visual da palavra que a aproxima da palavra falada. A falta de relação direta entre a palavra falada e a palavra projetada nos leva igualmente a encarar a possiblidade da palavra como elemento de desentendimento.

O Vivarium também brinca bastante com a forma visual das palavras. Um exemplo interessante aparece em Caspar Western Friedrich, onde os atores mostram, em uma determinada cena, um museu em construção. Quando eles instalam o letreiro com o nome do museu, eles o projetam com diferentes tipografias, percorrendo o leque das fontes mais batidas, saturadas e tidas como brega da história dos softwares 
de tratamento de texto, explorando igualmente o universo do WordArt ${ }^{17}$. Para além do efeito cômico do texto "decorativo", que utiliza efeitos modernos obsoletos, a projeção visual das palavras no teatro de Quesne não é anódina na reflexão sobre a voz em seu teatro. Ela propõe um dialogo entre a palavra falada a palavra escrita que tem funções dramáticas precisas, como citamos no caso de D'après nature. Essa imagem visual da palavra interfere, sem dúvida, na imagem sonora.

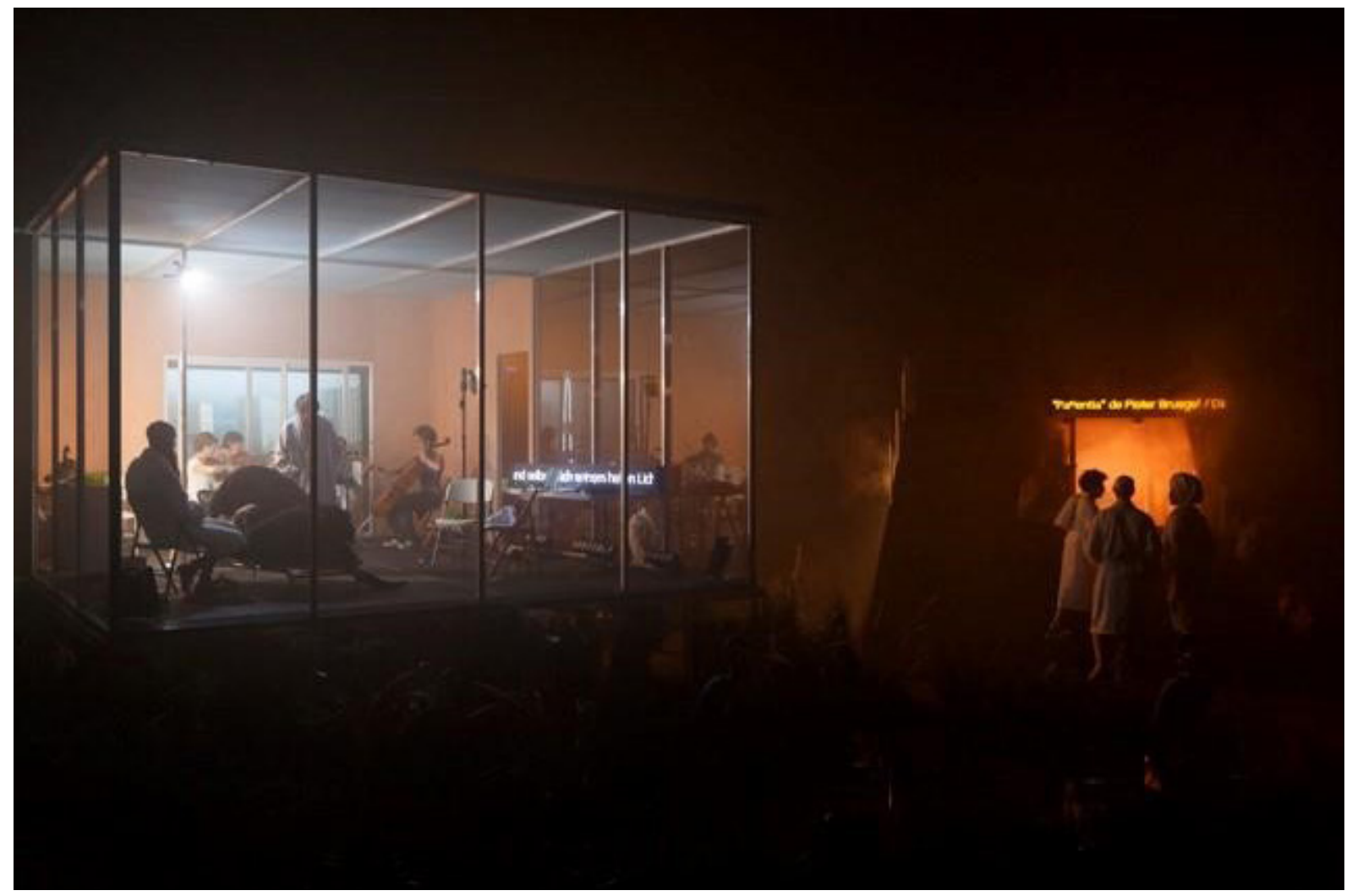

Imagem IV - Swamp Club (2013). Foto: Christophe Raynaud de Lage

\section{O uso do microfone}

Outro aparato tecnológico muito adotado por Quesne é o microfone. Ele pode assumir a estapafúrdia função de "ferramenta de atrapalhar" em certas peças. Em Caspar Western Friedrich, logo no começo do espetáculo um dos atores oferece a cada um dos outros um presente: um microfone em forma de pedra (Imagem V). Trata-se de uma pedra fake do tamanho de uma bola de futebol americano, pintada de cinza, na qual um microfone sem fio está acoplado. Os atores são compelidos a fazer uso desse instrumento para falar. $O$ incômodo corporal de mover-se e falar ao mesmo tempo manipulando a pedra-microfone interfere duplamente no gesto vocal dos atores. A postura do corpo que acompanha o ato de falar testemunha de uma "falta de jeito" devido ao desconforto de manipular o microfone, cuja forma não facilita seu uso. Esse incômodo interfere igualmente nos gestos vocais: os atores contorcem o

17 É um recurso de estilização de textos da Microsoft Office. Ele é visto como rudimentar e derrisório, como mostram sites humorísticos como este: http://www. buzzfeed.com/irangiusti/16-vezes-em-que-o-wordart-conseguiu-expressar-tudo-que-voce\#.wmYPBRVqV4. Consultado em 23 de março de 2016. 
pescoço tentando direcionar a boca no microfone e isso não facilita a fluidez do ato fonatório. Eles são assim obrigados a interromper as frases para adequar o corpo ao microfone.

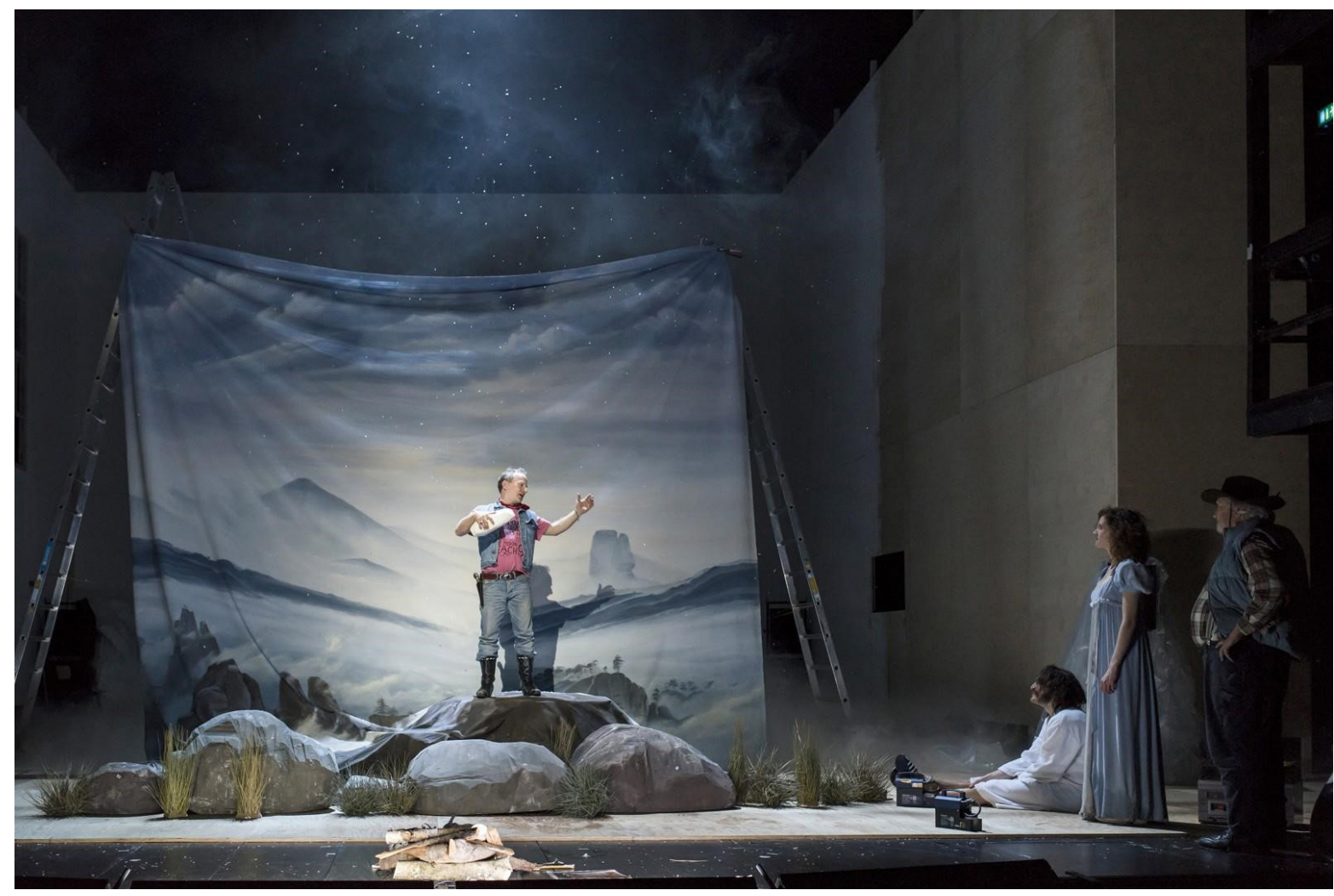

Imagem V - Caspar Western Friedrich (2015). Foto: Martin Argyroglo

No entanto, o principal uso do microfone no teatro de Quesne é outro. Esse recurso que, na história da vocalidade na música e nas artes cênicas, abriu diversas possibilidades à voz - como o aumento da potência vocal, a transformação da voz e sua "desencarnação" - é usado na estética quesniana para explorar sua fragilidade. Tal um microscópio sonoro, o uso do microfone no teatro de Quesne estabelece uma relação de proximidade entre o falante e seu auditor por meio da intimidade sonora gerada por sons que não podemos ouvir sem essa amplificação. Isso potencializa o efeito de "estar nu" em cena e favorece a posição do espectador como entomologista. Um exemplo é uma das últimas cenas do espetáculo La mélancolie de Dragons (2008), onde todos os atores se reúnem numa pequena cabine equipada com um microfone unidirecional para uma singela comemoração com champagne (Imagem VI). Os típicos silêncios constrangedores quenianos entre uma frase e outra são assim salpicados com o ruído da deglutição, o som da respiração dos atores e os ruídos de oclusão dos lábios. 


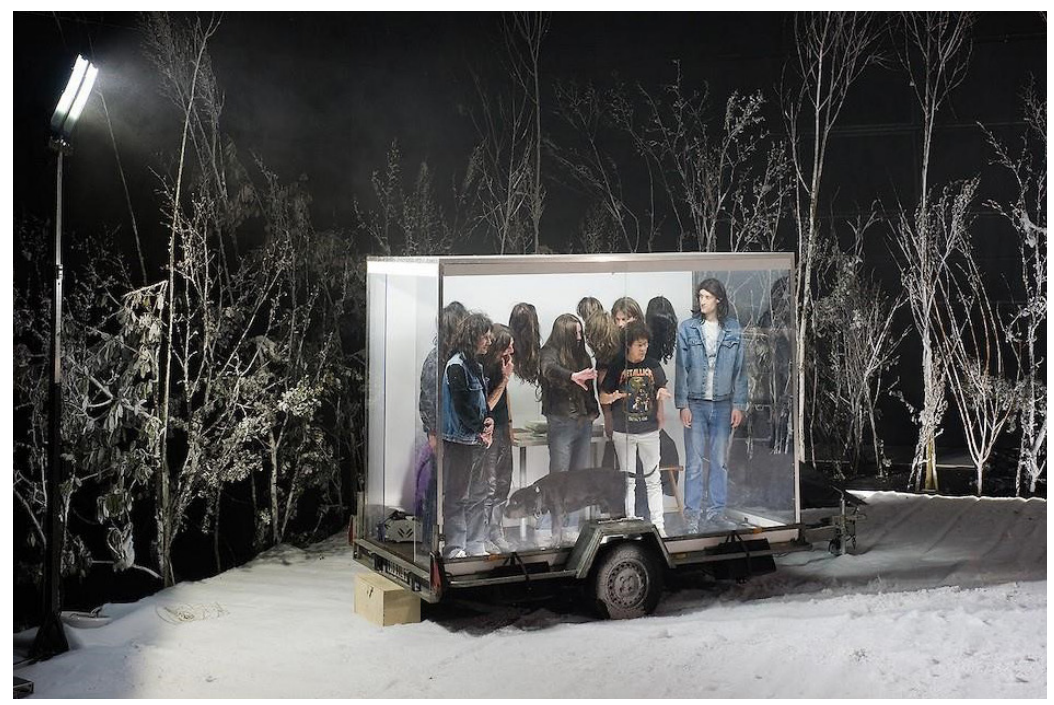

Imagem VI - La mélancolie des dragons (2008). Foto: Martin Argyroglo

\section{Conclusão: o que se perde quando se fala?}

"O que ainda não podemos dizer, já podemos talvez cantar" (Müller, 1970, p. $18)^{18}$. Essa máxima de Heiner Müller é retomada em numerosas obras de referência no âmbito dos Voice studies, do livro De la parole aux chants, organizado por Georges Banu (1995, p. 11), até Une Voix et rien d'autre, de Mlan Dolar (2012, p. 41), para citar apenas alguns exemplos. A recorrência dessa frase deve-se ao gosto pela musicalidade da língua no teatro contemporâneo. O teatro quesniano parece, quanto a ele, se ater ao aforismo original de Wittgenstein (1968, p. 129), que deu claramente origem ao de Müller: "o que não se pode falar, deve-se calar"19. Philippe Quesne dá voz "ao que se perde quando se fala" (Siéfert, 2013, p. 120)20. O Vivarium studio consegue tanger assim a relação paradoxal da necessidade humana da fala e a impotência da mesma, pela qual se interessou Vilém Flusser. $O$ filósofo exalta a relevância do gesto de calar-se - que, segundo ele, faz emergir a palavra absolutamente necessária - e do insistir em falar, apesar de não se acreditar na eficácia das palavras:

Trata-se de um gesto [o gesto de falar] destinado ao fracasso. Em última análise, os problemas fundamentais permanecem indizíveis e as falas pelas quais atingimos outrem permanecem inexprimíveis. O homem está condenado a não conseguir dizer o mundo e a permanecer só, apesar do esforço de falar. A fala é a moradia do ser, mas o homem nunca a possui e, quando ele é possuído por ela, não a domina. (Moisés e Demóstenes eram gagos). Mas é precisamente por causa de seu fracasso derradeiro que o gesto de falar é uma das manifestações da dignidade humana e propôs-se muitas vezes que ele definisse o ser humano, pois a dignidade humana é a tentativa de transpor esses limites, apesar do fracasso certeiro $^{21}$. (Flusser, 2014, p. 64-65)

\footnotetext{
18 "Was man noch nicht sagen kann, kann man vielleicht schon singen". (Tradução nossa).

19 Em alemão: "Wovon man nicht sprechen kann, darüber muss man schweigen". Tradução de José A. Gianotti.

20 "Je m'intéresse à ce qui se perd quand on parle". (Tradução nossa).

21 Il s'agit d'un geste [le geste de parler] commandé à l'échec. En dernière analyse les problèmes fondamentaux restent indicibles et les paroles grâce auxquelles on atteint autrui restent inexprimables. L'homme est condamné à ne pas pouvoir dire le monde et à rester seul, malgré son effort pour parler. La parole est la demeure de l'être, mais l'homme ne la possède jamais et quand il est possédé par elle, il ne la domine pas (Moïse et Démosthène étaient bègues). Mais c'est précisément à cause de son dernier échec que le geste de parler est l'une des manifestations de la dignité humaine et qu'on l'a souvent proposé pour définir l'être humain, car la dignité humaine c'est essayer de franchir ces limites malgré l'échec certain (l'hybris héroïque)". (Tradução nossa).
} 
Ao exaltar as falas ineloquentes, mal formuladas, além do incômodo de não saber o que dizer, Philippe Quesne explora um novo campo da vocalidade. Não se trata de utilizar a ineloquência como subterfúgio para exaltar a sonoridade da língua ou para dar mais possibilidades de impulsos à expressão corporal. A ineloquência é um fim em si.

\section{Referências}

Dicionário Priberam da Língua Portuguesa, 2008-2013. "Bisonho". URL: https://www. priberam.pt/dlpo/bisonho. Acesso: 8 fev. 2016.

BANU, Georges. De la parole aux chants. Arles: Actes-Sud, 1995.

DOLAR, Mladen. Une voix et rien d'autre. trad. Christine Vivier. Caen: Nous, 2012.

FERNANDES, Silvia e MEICHES, Mauro. Sobre o trabalho do ator. São Paulo: Perspectiva, 1988.

FLUSSER, Vilém. Les gestes. Bruxelas: Al Dante e Aca. 2014.

LEHMANN, Hans-Thies, O teatro pós-dramático. Tradução: Pedro Süssekind, São Paulo: Cosac \& Naify, 2007.

PAVIS, Patrice. Dictionnaire du théâtre: termes et concepts de l'analyse théâtrale. Paris: Éditions sociales, 1980.

Dictionnaire du théâtre. Paris: Armand Colin, 2002.

Dictionnaire de la performance et du théâtre contemporain. Paris:

Armand Colin, 2014.

PLANA, Muriel. "Le chant fragile de l'acteur. De l'usage « brutal » de la musique vocale sur les scènes contemporaines". In: Florence Fix, Pascal Lécroart e Fréderique Toudoire-Surlapierre (Org.) Musique de scène, musique en scène. Paris: Orizons, 2012, p. 204-213.

WITTGENSTEIN, Ludwig. Tractatus logico-philosophicus. trad. J. A. Gianotti. São Paulo: Companhia Editora Nacional e Editora da Universidade de São Paulo, 1968.

ZUMTHOR, Paul. "Oralité". In: BROWN, George; HAUCK, Gerd et LAURRUE, Jean-Marc (Org.). Intermédialités: Histoire et théorie des arts, des lettres et des techniques. Dossiê Mettre en scène, Montréal: Centre de recherche sur l'intermédialité - Université de Montréal, n. 12 , 2008. p.169-202. 
Entrevistas, encontros e conferências com Philippe Quesne e os membros do Vivarium Studio:

AKA, Nurten. L'homme, sa solitude, ses origines. Brussel Deze Week, Bruxelas, 20 de novembro de 2011, pp. 9-10.

Quesne, Philippe. Conferência de imprensa sobre La mélancolie des dragons, Festival d'Avignon, Avignon, 17 de julho de 2008. Disponível em: http://www.theatre-video. net/video/Conference-de-presse-du-17-juillet. Acesso em: 08 fev. 2016.

Entrevista para a equipe de Madeinavignon.com, École d'Art, Avignon, 08 de abril de 2008. Vídeo postado online pelo canal youtube Tv Avignon, 10 de abril de 2008. Disponível em: https://www.youtube.com/watch?v=AvYNi8mRHeg. Acesso em: 06 fev. 2016.

Conferência para o seminário Nouvelles théâtralités, Théâtre des Amandiers, Nanterre, 24 de janeiro de 2015.

QUESNE, Philippe. Des mots de minuit, France 2, 24 de março de 2010. Consultado nos arquivos do INA (Institut National de l'Audiovisuel).

Arte journal, Arte, 20 de julho de 2010.

SIÉFERT, Marion. Entrevista com Philippe Quesne para o Festival d'Avignon 2013, pp. 119-121, 2013. Disponível em: http://www.festival-avignon.com/fr/spectacles/2013/ swamp-club. Acesso em: 20 jan. 2016.

Recebido em: 30/04/2016

Aprovado em: 28/10/2016 
